\title{
EQUILÍBRIO LÍQUIDO-VAPOR DE SISTEMA AQUOSO COM MONOETILENOGLICOL À 350 mbar
}

\author{
A. K. FERNANDES ${ }^{1}$, D. J. SILVA ${ }^{1}$, M. P. HENRIQUE ${ }^{1}$, C. S. FIGUEREDO ${ }^{2}$, J. F. \\ NASCIMENTO $^{2}$, H. N. M. OLIVEIRA ${ }^{1}$ e O. CHIAVONE-FILHO ${ }^{1}$ \\ ${ }^{1}$ Universidade Federal do Rio Grande do Norte, Departamento de Engenharia Química \\ ${ }^{2}$ CENPES/PDEP/TPP, Cidade Universitária, Ilha do Fundão, Rio de Janeiro - RJ - \\ Brasil \\ E-mail para contato: karoline.equimica@hotmail.com
}

\begin{abstract}
RESUMO - A indústria de processamento de gás natural e condensados sofre com a formação dos chamados hidratos de gases que são comumente formados nas linhas de produção com condições ótimas de temperatura e pressão podendo impedir ou até mesmo paralisar o processo causando prejuízos. Os hidratos de gás são formados por associações de hidrocarbonetos leves e água produzida nas reservas de gás natural e apresentam-se na forma de cristais. Para combater esse problema, a indústria passou a utilizar inibidores termodinâmicos como o monoetilenoglicol (MEG) que são capazes de alterar o ponto de congelamento ou formação dos hidratos, além de ser higroscópico e poder ser regenerado. Atualmente as industrias de processamento de gás natural e condensado apresentam uma unidade apenas de Regeneração do MEG. Diante disso, visando conhecer o comportamento do inibidor aqui tratado, o trabalho teve como objetivo obter dados experimentais de Equilíbrio Líquido-Vapor do sistema binário água e MEG a pressão de 350 mbar.
\end{abstract}

\section{INTRODUÇÃO}

O gás natural ocorre naturalmente e é formado por misturas complexas de hidrocarbonetos leves com uma quantidade menor de compostos inorgânicos (HEIDEYRAN et al., 2010 a). Uma parcela desse gás está associada com a água produzida causando um dos maiores problemas da indústria de petróleo: A formação de hidratos de gás natural.

A água produzida ou "livre" (ROSSI, 1990), em baixas temperaturas e altas pressões congela e, consequentemente, "encapsula" as moléculas de hidrocarbonetos presentes formando estruturas cristalinas conhecidas como hidratos de gás (HEIDAYRAN et al, 2010 b). Esses hidratos, dependendo do tamanho podem até paralisar a atividade industrial causando prejuízos econômicos. 
Figura 1 - Hidrato de gás.

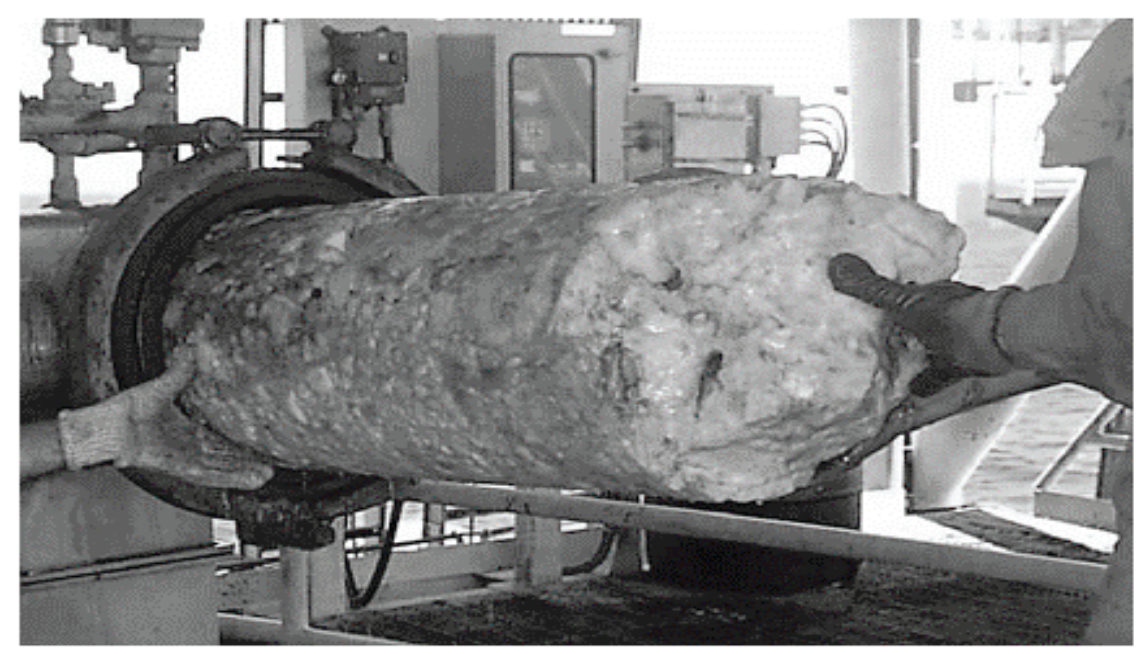

FONTE: Hydrates (2013)

Para combater o problema apresentado a indústria passou a utilizar inibidores termodinâmicos como o glicol chamado de MEG ou monoetilenoglicol. Ele apresentase com uma alternativa viável uma vez que é capaz de alterar o ponto de congelamento evitando a formação de hidratos, apresenta baixa toxidade, além de ser higroscópico, ou seja, capaz de reduzir a atividade da água no meio. O MEG pode também ser reutilizado no processo através de sua regeneração viabilizando seu uso com justificativa tanto econômica quanto ambiental. Assim, visando as Unidades de Regeneração do MEG disponíveis nas indústrias de processamento de gás natural, foram construídos diagramas de Equilíbrio Líquido-Vapor (ELV), a fim de observar o comportamento do MEG em meio aquoso e otimizar as atividades industriais.

\section{MATERIAL E MÉTODOS}

Os diagramas de ELV foram construídos a baixa pressão - 350 mbar. O método consiste na utilização de um ebuliômetro do tipo Othmer modificado que funciona de acordo com a recirculação da fase vapor, conforme ilustrado na Figura 2. Acoplado ao ebuliômetro está o banho termostático com temperatura estável em $5{ }^{\circ} \mathrm{C}$, agitadores magnéticos, o Fischer System que atua como controlador da pressão desejada. As variáveis temperatura e taxa de aquecimento são controladas através do programa computacional ACQDATA. 
Figura 2 - Ebuliômetro do tipo Othmer.

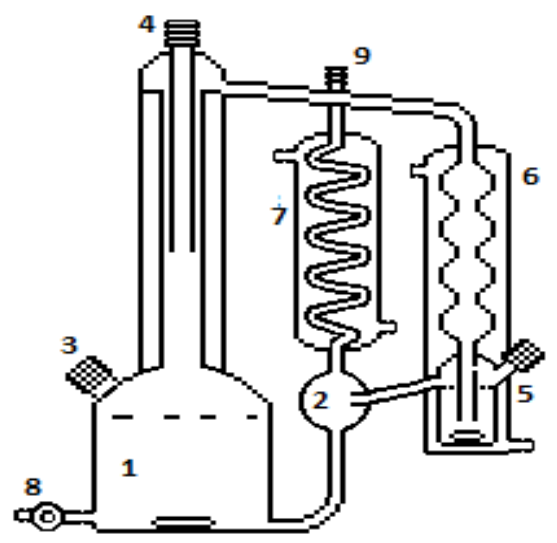

FONTE: Autor.

O equilíbrio termodinâmico é atingido quando a temperatura não varia depois de aproximadamente uma hora e meia. A umidificação interna no ebuliômetro, bem como um gotejamento da recirculação da fase vapor constante compõem as outras evidências de que o sistema binário estudado está em equilíbrio.

Com a análise da densidade, utilizando-se o densímetro digital Anton Paar, modelo 4500, é possível encontrar as frações mássicas e transformá-las em molar, de MEG no meio através de equações polinomiais obtidas em estudos anteriores da equipe, como a Equação 1 abaixo:

(1) $\chi=379,639565157 \rho^{3}-1178,312149175 \rho^{2}+1226,329136990 \rho-427,633869880$

Em que "“” é a fração mássica de MEG e o " $\rho$ " é a densidade obtida da solução ao final de cada experimento.

Foi usada a equação de Antoine (SMITH, ET al., 2000) com as seguintes constantes que estão na Tabela 1.

Tabela 1. Constantes da Equação de Antoine

\begin{tabular}{|c|c|c|}
\hline Constantes de Antoine & MEG & ÁGUA \\
\hline A & 7,76432 & 8,07131 \\
\hline B & 1851,1880 & 1730,630 \\
\hline C & 181,744 & 233,426 \\
\hline
\end{tabular}




\section{RESULTADOS E DISCUSSÕES}

As curvas de equilíbrio do sistema binário MEG e água foram construídas relacionando a temperatura $\left({ }^{\circ} \mathrm{C}\right)$ e fração de MEG variando de 0 à $100 \%$ sendo comparados com o Modelo de Antoine que foi o adotado ao sistema estudado na pressão de 350 mbar. Foi construída uma curva de Pressão de Vapor de MEG puro versus temperatura, Gráfico 2, mostrando que nossos resultados estão confiáveis, uma vez que se faz a comparação com dados de pressão de Vapor de MEG da literatura com os dados experimentais obtidos. Os Gráficos 1 e 2 apresentam esses resultados.

Gráfico 1- Curva de ELV à 350 mbar. Dados experimentais e Modelo de Antoine.

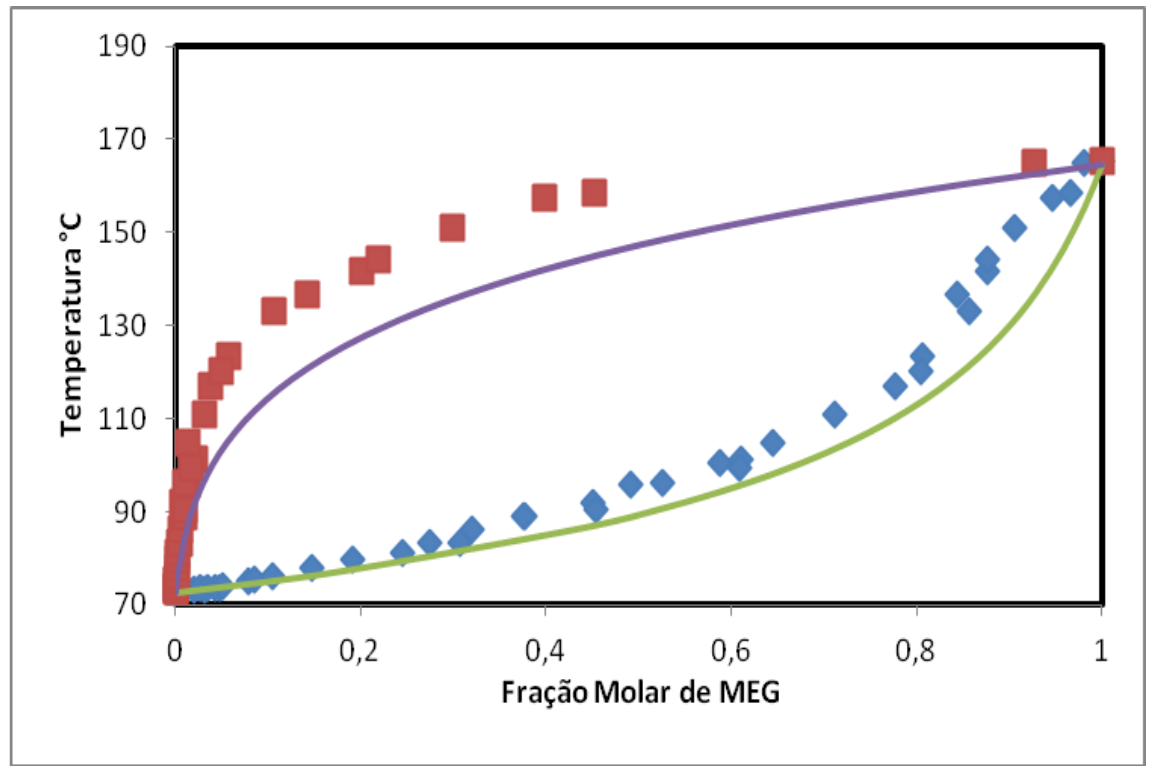

Gráfico 2 - Pressão de vapor do MEG puro versus temperatura.

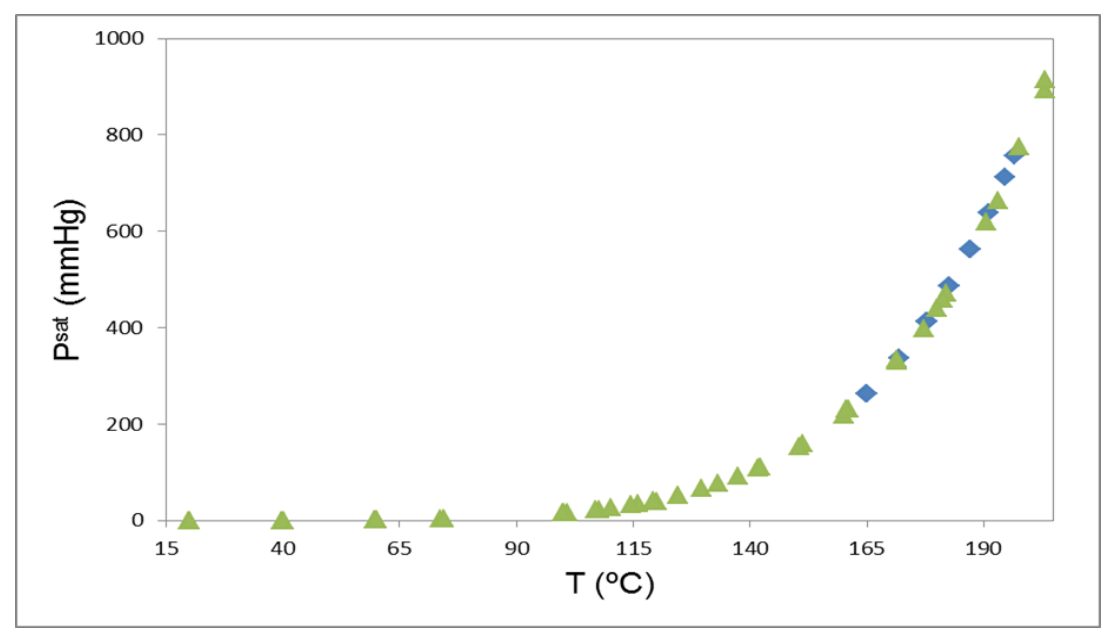




\section{CONCLUSÃO}

É possível concluir que os resultados experimentais foram de acordo com o esperado de acordo com o Modelo Antoine viabilizando o estudo do ELV do sistema binário água e Meg e possibilitando estudos com novos sistemas aquosos envolvendo MEG. A modelagem dos dados permitirá também a avaliação e o projeto dos processos de evaporação e destilação da unidade de regeneração do MEG, usualmente implantada em plataforma.

\section{REFERÊNCIAS}

HEIDARYAN, E.; SALARABADI, A.; MOGHADASI, J.; DOURBASH, A.

A new high performance gas hydrate inhibitor, J. of Natural Gas Chemistry, 19, 2010 a, p. 323-326.

HEIDARYAN, E.; MOGHADASI, J.;MASOUD, R.

New correlations to predict natural gas viscosity and compressibility factor. J. of Petroleum Science and Engineering, 73, 2010 b, p. 67-72.

HIDRATOS. FORMAÇÃO DE HIDRATOS. Disponível em:

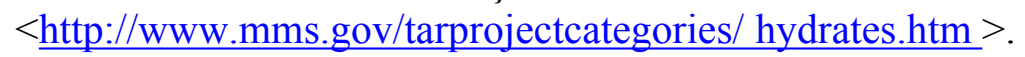

ROSSI, L. S. F. Formação de hidratos em sistemas de gás natural.

Dissertação de Mestrado, FEM/UNICAMP, Campinas, SP, Brasil, 1990.

SMITH, J.M.; VAN NESS, H.C.; ABBOTT, M.M.

Introdução à Termodinâmica da Engenharia Química. $5^{\mathrm{a}}$ Edição. LTC EDITORA, 2000. 